Revista Aspas

ppgac - USP

Artigo

\title{
ARQUIVO E REPERTÓRIO NA PERFORMANCE DE ROLANDO BOLDRIN
}

\author{
ARCHIVE AND REPERTOIRE IN THE \\ PERFORMANCE OF ROLANDO BOLDRIN
}

\section{ARCHIVO Y REPERTORIO EN LA PERFORMANCE DE ROLANDO BOLDRIN}

\section{Pedro Isaias Lucas}

Pedro Isaias Lucas

Doutorando em Artes Cênicas da Universidade

Federal do Rio Grande do Sul. Pesquisa em andamento na área de Processos de

Criação, com orientação da Profa. Inês Alcaraz Marocco. Realizador audiovisual.

E-mail: arteriacine@gmail.com 


\section{Resumo}

Este artigo analisa a prática performática do ator e contador de causos Rolando Boldrin e sua relação com a prática arquival, a partir do acompanhamento de uma gravação do programa de televisão Sr. Brasil da TV Cultura, colocando em perspectiva a observação de fatos relacionados à formação desse ator decano. $O$ texto também sugere a influência da utilização de métodos da cartografia na observação da performance de Boldrin e na produção de dados realizada pelo autor. Palavras-chave: Ator, Contador de causos, Memória.

\section{Abstract}

This article analyzes the performative practice of the actor and storyteller Rolando Boldrin and his relationship with the archival practice, from the accompaniment of a recording from the television show Sr. Brasil in TV Cultura channel, putting in perspective the observation of facts related to the formation of this actor. The text also suggests the influence of the use of cartographic methods in the observation of the Boldrin's performance and in the production of data performed by the author.

Keywords: Actor, Storyteller, Memory.

\section{Resumen}

Este artículo analiza la práctica performativa del actor y contador de historias Rolando Boldrin y su relación con la práctica archivística a partir del acompañamiento de una grabación del programa televisivo Sr. Brasil, de la TV Cultura, en perspectiva con la observación de hechos relacionados a la formación de ese actor. El texto también sugiere la influencia de la utilización de métodos de la cartografía en la observación del desempeño de Boldrin y en la producción de datos realizada por el autor.

Palabras clave: Actor, Contador de historias, Memoria.

\section{Só de ouvido}

A referência mais antiga que lembro de ter ouvido sobre Boldrin foi um elogio de meu pai ao programa de música brasileira daquele "caboclo" de olhar transparente que, no início dos anos 1980, apresentava o programa 
Som Brasil, veiculado pela Rede Globo de Televisão nas manhãs de domingo. Da aprovação de meu pai até a minha própria constatação da força expressiva daquele programa, se passaram décadas. E o que em princípio era uma aprovação paterna da autenticidade da cultura interiorana - da qual o apresentador se valia para ambientar a prosa com os seus convidados -, com o tempo cedeu espaço à minha própria admiração pela agilidade daquele senhor em representar vários personagens enquanto narrava seus causos. Somado a isso, há a música. Muitas das quais ouvíamos quando ainda éramos muito pequenos e, se não foram fixadas por nossa memória infantil, não escapam da familiaridade persistente.

Boldrin começou a se apresentar na estação de rádio da sua cidade natal aos onze anos de idade em uma dupla com seu irmão mais velho. Ambos tocavam e cantavam "modas de viola, toadas e cateretês" (BOLDRIN, 2007, p. 15). A dupla mirim participou da inauguração da Rádio São Joaquim, na cidade de São Joaquim da Barra, região oeste do estado de São Paulo. Depois da inauguração Boldrin continuou participando de programas musicais da estação. No aprendizado do violão ele foi um autodidata que buscava assistir de perto os antigos tocadores de viola da sua região. Ele aprendeu os primeiros ponteios com um caboclo e o resto foi descobrindo por si mesmo ou observando outros violeiros. O pai de Boldrin, Amadeo, incentivava-o a trabalhar com música pois via no rádio um meio de sustento possível para quem não teria condições de estudar muito. Seu Amadeo, que era mecânico de automóveis, sabia que não poderia oferecer condições para que o filho estudasse além do ensino médio.

O gosto por contar causos começou tão cedo que Boldrin nem lembra quando aconteceu. Ele afirma que sempre gostou de "observar tipos humanos de todas as idades" e de prestar atenção às histórias engraçadas ou tristes que eles contam (BOLDRIN apud ABREU, 2005, p. 27). Para Boldrin, a audição da história é indissociável da observação dos recursos narrativos e dos caracteres culturais com os quais o orador trabalha. Essa capacidade de escuta, de observação, esse interesse em captar os detalhes dos acontecimentos e a maneira como os envolvidos agiram durante os fatos, Boldrin associa ao início de sua formação como ator. Além do exercício vocal, a narração de histórias 
exigia a execução de um repertório gestual e de posturas corporais que não eram cotidianas para um menino da sua idade. Era preciso portar-se como um boiadeiro, um delegado ou um pescador. Ele contava causos na Rádio São Joaquim, que eram transmitidos por meio dos alto-falantes instalados em praças em várias cidades do interior. No auditório da estação onde o programa de rádio era produzido, uma plateia também assistia ao vivo a performance do menino.

Aos dezesseis anos de idade, Boldrin foi para São Paulo. Trabalhou como auxiliar de sapateiro, garçom, ajudante de farmacêutico e outros serviços no comércio da capital paulista. Depois do serviço militar obrigatório no interior do estado de São Paulo, ele decidiu voltar à capital com a intenção de trabaIhar em uma das emissoras de rádio daquele período. Boldrin tornou-se candidato para as vagas que surgiam para ator de radionovela, locutor ou cantor nas rádios São Paulo, América e Itapetininga. Nessa disputa pelas chances que apareciam, foram mais de 3 anos fazendo testes e entrevistas. Enquanto isso, ele passava de um emprego temporário a outro, para garantir o sustento. "A última tentativa foi na rádio e TV Tupi, a pioneira do Brasil" (BOLDRIN, 2007 , p. 23). No primeiro teste, para cantor, ele foi reprovado. Porém, foi aprovado para a vaga de ator de rádio. O ano era 1958 e todos os artistas que eram selecionados pela rádio Tupi eram aproveitados também na televisão da emissora, a primeira estação de emissão televisiva do Brasil, que inaugurara a teledifusão do seu sinal oito anos antes.

\section{Pelo telefone}

Obtive o telefone da agente de Boldrin a partir de um labirinto de contatos telefônicos com a TV Cultura de São Paulo. Depois de algumas tentativas, em um dos dois números de telefonia fixa que me haviam fornecido, uma pessoa atendeu e perguntou o que eu queria. Eu disse que precisava falar com a Patrícia Maia. Uma voz masculina, de idade indefinível, pediu que eu ligasse mais tarde. Horas depois, a mesma voz atendeu e perguntou quem eu era e o que eu queria com a Patrícia. Contei-Ihe a minha condição de doutorando, falei sobre a pesquisa para explicar por que eu precisava falar com a agente de Boldrin. De imediato aquela voz me respondeu: "O Rolando 
Boldrin sou eu. E a Patrícia é minha esposa!". Tomado de surpresa e com uma incômoda sensação de despreparo, narrei os motivos da escolha dele para a pesquisa e da necessidade de assistir alguns de seus ensaios e gravações de programas. Ele respondeu "O Boldrin tem e-mail, anota aí o endereço dele!" com uma voz grave e sem nenhum traço do sotaque interiorano, uma das características marcantes do apresentador do programa Sr. Brasil na televisão. Ouvir ele se referindo ao Boldrin em terceira pessoa e sem sotaque aumentou ainda mais a minha confusão. Enquanto anotava o e-mail, perguntei se era possível acompanhar alguns de seus processos de trabalho, e ele disse que sim, que era só marcar com a Patrícia, porque o "Boldrin está cheio de serviço". Ainda sem saber ao certo com quem eu estava falando de fato, contei a ele as expressões que o meu pai usava para qualificar aquele "caboclo" apresentador de programa de música brasileira. Quando ouvi a risada do outro lado da linha telefônica, percebi que estava realmente falando com Boldrin. Constatei também que é muito difícil reconhecer um ator veterano do rádio "só de ouvido" e que, por trás de uma voz polida, séria e urbana, pode estar em ação um "matuto" que se diverte causando confusão na cabeça dos "doutorzinhos", a exemplo de alguns personagens dos seus causos. Antes de nos despedirmos, ele finalizou: "Então tá, manda um e-mail para o Boldrin!". Depois de desligar o telefone, passei um tempo rememorando cada frase que havíamos trocado recentemente. Ainda perplexo, suspeitei pela primeira vez que o apresentador do programa de música na televisão, tão popular desde 1980 devido à sua fala popular e interiorana, fosse de fato um personagem criado pelo ator Rolando Boldrin. Um dia depois de enviar um e-mail para ele, veio a resposta:

Oi Pedro. Desculpe a demora [na resposta]. No momento não tenho tempo disponível para um gostoso papo sobre as "coisas." Para marcar um dia pra você assistir uma gravação, vou te passar a minha produtora PATRICIA. Diga-lhe que estamos falando sobre isso e ela vai ver qual será a melhor opção de data [da Gravação]. Abraços. ROLANDO.

Depois de ler a mensagem dele, resolvi não insistir em fazer a entrevista nesse primeiro momento. Decidi que era melhor aproveitar as ocasiões que me foram permitidas, para oportunizar um melhor esclarecimento a respeito 
da abordagem do estudo a ser realizado e, talvez, despertar alguma simpatia de Boldrin e de sua agente para com o meu projeto de pesquisa. Apesar da frustração com a recusa em conceder uma entrevista, fiquei satisfeito com a impressão que esse primeiro contato com Boldrin causou em mim. Aquela breve conversa por telefone, seguida por uma troca de e-mail, me provocou uma desconfiança a respeito de quais traços do personagem - que Boldrin criou para apresentar seu programa de televisão - eram características pessoais do próprio ator. Talvez, algumas dessas características, como o trato atencioso com seus interlocutores e a fala direta e sem cerimônias, pudessem favorecer a realização da pesquisa.

Virgínia Kastrup afirma que a separação entre o objeto científico e o cientista foi criada pela ciência moderna para garantir a validade do saber pela comunidade científica. A partir disso, foi criado o dispositivo experimental que seria capaz de por à prova as invenções do pesquisador ou provar que tais invenções são, na verdade, descobertas. Para Kastrup, esse dispositivo cria, de fato, uma hierarquia das invenções ao classificar como válidas as que podem ser chamadas de legítima descoberta, ou inválidas as que são mera invencionice. O resultado disso seria a "ocultação da invenção" no processo de produção de conhecimento e a consequente representação de objetos selecionados pelo dispositivo experimental (PASSOS; KASTRUP; ESCÓCIA, 2014, p. 55).

Priorizar uma invenção dentre outras e considerá-la uma descoberta, caracterizaria, portanto, uma representação de aspectos do fenômeno estudado. De outra parte, considerar a participação do pesquisador na produção dos dados seria, então, uma oportunidade para revelar o conjunto de invenções que o pesquisador opera e que, de maneira direta ou indireta, também condicionam a atenção dele no trabalho de pesquisa. Sendo assim, ao utilizar os métodos cartográficos o pesquisador se coloca na condição de observador participante. Ele inventa formas de se colocar em contato com uma pessoa e de habitar um território alheio, do qual ele pouco ou nada conhece, que é o "território existencial" dessa pessoa (PASSOS; KASTRUP; ESCÓCIA, 2014, p. 56). Por isso, a cartografia não é uma metodologia com procedimentos fixos. Pelo contrário, a abertura para a inventividade que a cartografia propõe é, também, uma maneira de manter em constante revisão e adaptação os procedimentos utilizados. O importante é conseguir entrar em contato e habitar, 
ainda que temporariamente, o território do outro e acompanhar alguns de seus processos.

\section{Ao vivo}

Estou sentado na segunda fileira do lado direito do teatro Pompéia. Antes de iniciar mais uma gravação do programa Sr. Brasil, um sinal sonoro é emitido. Depois desse sinal o burburinho cessa e emerge um silêncio, que prepara a introdução dos primeiros acordes de dois violões, que logo são reforçados pelo som suave de um acordeão. Boldrin em pé, ao lado dos músicos, inicia a declamação de um poema. As pausas entre as frases que ele recita dão tempo para que uma frase musical fique em evidência e potencialize o efeito das palavras recém pronunciadas. Boldrin inicia uma nova sentença no momento em que uma nova frase musical também inicia, sincroniza a sua fala com a intermitência e as variações tonais do arranjo instrumental. Um olhar arregalado marca a virada do saudosismo do personagem, para um sutil desconforto, expresso pelo relaxamento dos músculos da face e uma certa tensão nas pálpebras dos olhos. O poema fala sobre o sentimento de um agricultor por sua lavoura de café. Um sorriso quase imperceptível reaparece durante uma pausa prolongada que antecede a última frase do poema. Ninguém aplaude. Ele se senta em uma cadeira de madeira e palha, enquanto o volume da música aumenta. Um dos violeiros, de pé, executa a introdução que prepara o início dos primeiros versos da música que ele começa a cantar: "Eu quero uma casa no campo. Onde eu possa compor muitos rocks rurais". Trata-se de uma música considerada um emblema da vida campestre e que foi gravada pela cantora Elis Regina. O arranjo da canção, com dois violões e o acordeom, é bem elaborado, sem ser rebuscado. Boldrin observa-os sorrindo. Na última frase da música, a plateia canta em coro. Boldrin se levanta da cadeira e aplaude de pé.

Quando os aplausos cessam, ele pede ao violeiro mais antigo que se sente: "Se abanque aí compadre!.' A seguir, apresenta os violeiros e compositores Tavito e Cláudio Nucci e o acordeonista Abraão Lincoln. Nucci afirma que conheceu Tavito quando o seu conjunto, o Boca Livre, foi até o apartamento do compositor veterano para pedir alguns conselhos a respeito da gravação 
de seu primeiro disco. Boldrin observa que a música recém-tocada foi gravada por muita gente e pergunta qual foi a versão que mais fez sucesso. Tavito lembra que o compositor Zé Rodrix escreveu a letra durante uma viagem entre Goiânia e Brasília, quando ambos excursionavam como músicos de apoio da cantora Gal Costa. No hotel, Rodrix passou a letra para Tavito, que musicou a canção em poucos minutos, sem fazer alterações no poema. Segundo ele, o resultado desagradou a ambos. Ao ouvir isso, Boldrin solta uma gargalhada. Tavito ri também e explica que esse tipo de rejeição era comum nas parcerias que fazia com Rodrix. Boldrin franze as sobrancelhas, como quem tenta confirmar o que ouvira. Tavito confirma com um balanço de cabeça e lembra que eles inscreveram a música em um festival, no qual a cantora Elis Regina fazia parte do corpo de jurados.

Boldrin pede para que eles aproveitem o embalo e cantem mais uma canção. Porém, Tavito argumenta que foi ao programa Sr. Brasil para ouvir causo. Boldrin olha para ele e afirma que isso o havia feito lembrar de um caboclo lá da terra dele, em São Joaquim da Barra, chamado Zé Pitanga, que tinha a particularidade de andar sempre apressado. Boldrin olha para a plateia e sentencia: "Ele chegava no bar como se estivesse atrasado para chegar no serviço". Boldrin arregala os olhos e esfrega uma mão na outra enquanto diz: "Ele chamava todo mundo de cidadão e fazia assim com a mão: 'Me dá um café aí!' Vinha o café e ele..., Boldrin, com a mão direita, faz de conta que segura apressadamente uma taça de café imaginária e se põe a assoprar seu conteúdo antes de toma-lo de um gole só. "Ele assoprava, tomava e ia para outro bar." Boldrin aponta com o dedo para longe e, depois de uma pausa, sentencia: "Ele não trabalhava. Só andava pela rua de bar em bar. E sempre com pressa." A plateia e os músicos convidados riem. "Um dia eu fui visitar a minha família e, conversando com uns amigos na frente da igreja, no bar central, perguntei: 'e o Zé Pitanga? Onde ele anda?'” Boldrin olha para os convidados e comenta: "Eu adorava ele!". A seguir, olha para a plateia e reforça o sotaque: "Acho que mataram ele!', o outro falou 'Morreu, mas não mataram ele não, foi de morte natural. $O$ filho dele contou para mim"' Boldrin faz uma pausa e retoma a narrativa apontando com o dedo um ponto distante: "Daí eu vi quando passou um cara rápido, entrou num bar e fez assim." Esfrega as mãos apressadamente. "Que coincidência! Era ele! Daí eu chamei: 'Zé!' Ele 
me olhou lá do outro lado e..." assoprando uma taça de café imaginária e depois fazendo sinal com a mão espalmada: "espera aí cidadão!". A plateia e os músicos convidados riem. "Ele tomou o café rápido e veio. Ele usava um terninho de brim caqui. E chegou: 'Pois não cidadão!?' 'Ô Zé, o pessoal tá falando que você morreu. Por onde você andou rapaz? Você sumiu!', daí ele, que nunca tinha trabalhado na vida, disse: 'Eu tô trabalhando em Orlândia!'” Boldrin faz uma voz grave e decidida, que demonstra uma certa irritação de quem quer encurtar a conversa. A seguir, ele olha para a plateia e diz sorrindo: "Orlândia é uma cidade a $20 \mathrm{~km}$ da minha terra. E repete: 'Eu tô trabalhando em Orlândia!', mas, quando ele falou a palavra trabalhando, um olhou para o outro e fez assim...," Boldrin passa a mão pelo queixo e desvia o olhar para o chão. “Disfarçando... Eu percebi e perguntei: 'Você faz o que lá?' e ele: 'Eu tô trabalhando de guia de um cego!"' Risos na plateia, Boldrin faz uma pausa. "Daí um deles falou: 'Ô Zé, mas você nem conhece Orlândia!'” $E$ Boldrin com um gesto enérgico, dedo indicador apontando para baixo, arremata: "daí ele falou: 'Mas o cego conhece!"' Todos riem, até mesmo eu, que tentava anotar e observar ao mesmo tempo, e me sentia um tanto distante do estado de relaxamento que a maioria da plateia parecia aproveitar naquele momento, não me contive e ri junto com o pessoal. Naquele momento, fiquei com a impressão de que Boldrin também se divertia, mesmo conhecendo esse causo há muito tempo.

\section{Considerações}

A atividade de Boldrin como ator e contador de causos é ratificada pela forma e pelos critérios de funcionamento do evento, que ele próprio concebeu e também dirige. $O$ evento em si reafirma o caráter memorialístico, que também é observável no trabalho do contador de histórias. Isso equivale dizer que, assim como a narração de histórias, o modo como o evento de auditório é produzido opera para evitar que formas de agir e de ver o mundo sejam esquecidas. A exemplo do narrador que, ao contar histórias torna memorável uma seleção de personagens e peripécias, o programa conduzido por Boldrin funciona como um marcador de relevância e de mérito, que cultiva a memória de personagens populares e suas histórias. O contexto de criação das músicas 
e os fatos que possibilitaram a existência delas são validados como parte da cultura artística do Brasil. O programa, a partir da seleção dos seus convidados e da natureza da conversa que ali se desenvolve, oferece uma narrativa própria sobre a música regional e popular, que sempre carecem de espaço para serem veiculadas. Tanto Tavito quanto Cláudio Nucci estão ausentes na vitrine da indústria musical há bastante tempo, apesar da estatura da obra de ambos. Suas músicas, apesar da razoável circulação nacional de outrora, têm execução restrita nos dias atuais. A presença deles performando as próprias músicas causa uma espécie de déjà vu na plateia. $O$ frescor da descoberta e a sensação de que ela toca em alguma lembrança antiga, que é difícil de identificar. Na plateia, a sensação de rememorar se torna uma experiência coletiva, em que a participação do outro é relevante e imprescindível.

Em um país de território vasto, como o Brasil, habitado durante milênios por populações que preservaram os rios e as florestas no período pré-colombiano, cujo histórico de colonização europeia teve feições agrárias, extrativistas, e que é marcado por um processo de industrialização e de concentração populacional nas áreas urbanas, é de se esperar que referências à passarada, ao banho de rio ou à cabana de madeira sejam uma saudação ao estilo de vida mais antigo. Para muitas pessoas no Brasil, falar do mato, das lavouras ou da boiada é como falar das origens da própria família. A referência a esses assuntos mexe com afetos e experiências sensoriais vividas ou apenas imaginadas a partir das histórias contadas pelos mais antigos.

Boldrin conta histórias em que os personagens são conhecidos dele, ou de alguém que ele conhece. Talvez, para tornar a peripécia mais verídica, é possível que algumas das histórias ele tenha adaptado para poder se incluir no fato narrado. Mas o importante é que ele nos faz acreditar que tudo se passou em sua presença, ou com um conhecido dele, efetuando, assim, um procedimento que a pesquisadora Luciana Hartmann (2009, p. 75) também identificou em sua pesquisa sobre contadores de histórias da fronteira do Rio Grande do Sul. A autenticidade conferida pelo fato de a história ter acontecido com o próprio Boldrin ou com um compadre dele amplia o efeito que a peripécia causa no ouvinte, principalmente, se o desfecho for jocoso, como é o causo do Zé Pitanga. $O$ fato dele ter conhecido Zé Pitanga também legitima a imagem que ele constrói para o personagem. Boldrin escolhe um traço da personalidade de 
Zé Pitanga e reforça-o: a pressa. Durante a narração do causo, sabemos que quem está falando é Zé Pitanga porque ele esfrega uma mão na outra, agita-se e fala apressadamente. Quando Boldrin faz um aparte para a plateia depois de uma fala do personagem, em contraste, ele pronuncia as palavras calmamente e às vezes sorrindo, ao contrário do jeito de Zé Pitanga falar, sempre sério e apressado. Os gestos de Boldrin às vezes substituem as palavras e, às vezes, as contextualizam ou complementam. O gestual de Zé Pitanga assoprando o café e esfregando uma mão na outra, em conjunção com a informação passada oralmente de que o personagem nunca trabalhou na vida, apesar de parecer estar sempre atrasado para o serviço, torna a situação ainda mais engraçada. Essa alternância entre gesto e palavra também é um dispositivo para fazer o ouvinte engajar-se na história contada.

O gestual de Boldrin ao interpretar o personagem Zé Pitanga condiciona também o som da voz diegética. Os sons emitidos durante a execução dos gestos apressados possuem caracteres que a agitação do corpo produziu. $O$ ouvinte percebe tudo isso como um todo orgânico, o que ajuda a concretizar a presença do personagem diante dele. O engajamento do ouvinte instiga o narrador. Percebendo que a plateia o acompanha durante a narrativa, ele pode intuir as formas viáveis para manter a atenção dela. Isso faz com que cada texto seja único, ainda que a mesma história seja repetida várias vezes. A forma de contar a história está sujeita a variações que dependem de quem a está ouvindo também. Isso coloca a contação de causos no âmbito da experiência, e como tal, ela é única, mesmo que seja repetida em outras ocasiões. Há nisso um componente estético que opera junto com o ato comunicativo.

O causo do Zé Pitanga está ambientado no universo interiorano de São Joaquim da Barra e região. O personagem é uma espécie de malandro, um outsider que mora em uma cidade pequena, onde é mais difícil de se esconder as próprias excentricidades. A abordagem que Boldrin faz desse personagem não o reduz a um perfil previsível. A performance de Boldrin mantém o mistério que paira sobre a organicidade dos atos e costumes de Zé Pitanga: a estratégia utilizada para disfarçar o fato de não trabalhar. Manter-se apressado como os que trabalham e chamar aos outros de "cidadão". A postura e a voz do personagem foram corporificadas por Boldrin de forma que expressam integridade, inteireza. A performance dele elimina a possibilidade de uma 
interpretação que veja dubiedade, vigarice ou mau-caratismo na personagem de Zé Pitanga. Quando cito a performance de Boldrin, utilizo a ideia de evento oral e gestual, descrita por Paul Zumthor (2014, p. 41) como "quando os elementos se cristalizam em torno da lembrança da presença", ou seja, uma atualização incorporada da memória. A incorporação que Boldrin realiza explicita a identificação dele com práticas vivas de uma parte da população que também transmite prioritariamente os seus aprendizados a partir de ações incorporadas. A performance de Rolando Boldrin está alicerçada no que Derrida (2001, p. 32) definiu como uma "pulsão de arquivo," exercida pelo ator desde a sua própria infância. A forma utilizada para o exercício dessa pulsão foi o aprendizado a partir da observação e incorporação de performances de populares que lhe cativavam a atenção. A seleção e incorporação do "repertório" (TAYLOR, 2013, p. 49) de pessoas iletradas se configuram um ato político na medida em que Boldrin vivifica práticas em constante risco de desaparecimento, devido à efemeridade intrínseca e à vulnerabilidade de seus praticantes. Em uma circunstância de perda definitiva de repertório, as pessoas que têm suas memórias aniquiladas são as mesmas que praticaram a sua cultura mestiça como um meio de existência, de sobrevivência, de adaptação às forças restritivas de um processo colonial persistente, cuja violência molda e fere as formas dessa mestiçagem desde a sua origem.

O ato performático de Boldrin incarna a cultura popular brasileira e reage à truculência e à sabotagem a qual essa cultura está constantemente submetida. E o repertório vivo desse ator, ao ser registrado pelas câmeras de televisão, passa a ter uma versão arquivável de alto potencial de difusão. Mas, como nos adverte Diana Taylor em seu livro $O$ arquivo e o repertório, "a performance ao vivo nunca pode ser captada ou transmitida por meio do arquivo" (TAYLOR, 2013, p. 50). O arquivo audiovisual registrado pelas câmeras não tem capacidade para fixar uma multiplicidade de aspectos da ação viva desse ator. O volume razoavelmente baixo de sua voz modulada, a inteireza dos seus movimentos e o jogo com a plateia são precariamente perceptíveis em um registro televisivo. Contudo, os caracteres da performance de Boldrin que esse tipo de arquivo consegue manter adquirem perenidade. E com isso, fragmentos de repertório vulnerável talvez tenham assim uma forma de conservação. $E$ se esses fragmentos arquivados não servirem para estudos futuros 
sobre performance, talvez sejam úteis ao estudo da cultura popular e sua relação com o processo civilizatório brasileiro.

\section{Referências bibliográficas}

ABREU, leda. Palco Brasil: Rolando Boldrin. São Paulo: Imprensa Oficial, 2005.

BOLDRIN, Rolando. História de amar o Brasil: 50 anos de carreira artística.

São Paulo: [s. n.], 2007.

DERRIDA, Jacques. Mal de arquivo: uma impressão freudiana. Rio de Janeiro:

Relume Dumará, 2001.

HARTMANN, Luciana. Corpos que contam histórias: performance e identidade de "contadores de causos" da fronteira. OTeatro Transcende, Blumenau, v. 15, n. 15,

p. 16-25, 2009. Disponível em: https://bit.ly/2WEZH3e. Acesso em: 1 maio 2016.

PASSOS, Eduardo; KASTRUP, Virgínia; ESCÓCIA, Liliana (org.). Pistas do método

da cartografia. Porto Alegre: Sulina, 2014.

TAYLOR, Diana. 0 arquivo e o repertório: performance e memória cultural nas

Américas. Belo Horizonte: Editora UFMG, 2013.

ZUMTHOR, Paul. Performance, recepção, leitura. São Paulo: Cosac Naify, 2014.

Recebido em 11/02/2019

Aprovado em 24/05/2019

Publicado em 29/08/2019 